\title{
YARN UNWINDING FROM PACKAGES
}

\author{
Predovič Aleksander
}
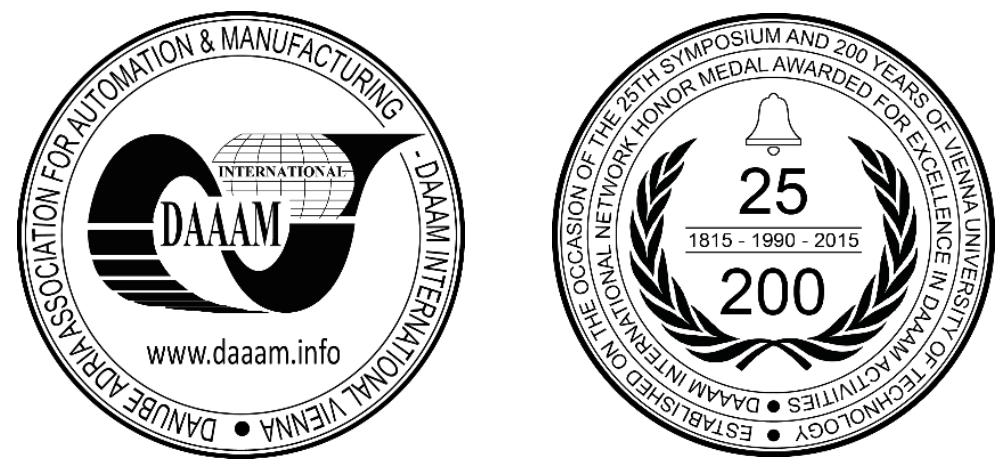

This Publication has to be referred as: Predovic, A[leksander] (2017). Yarn Unwinding from Packages, Proceedings of the 28th DAAAM International Symposium, pp.0698-0703, B. Katalinic (Ed.), Published by DAAAM International, ISBN 978-3-902734-11-2, ISSN 1726-9679, Vienna, Austria

DOI: $10.2507 / 28$ th.daaam.proceedings.098

\begin{abstract}
The Yarn unwinding from a package is important in many textile processes. The stability of the unwinding process has a direct influence on the efficiency of the process and on the quality of the end product. During the unwinding, the tension is oscillating. This is especially noticeable in over-end unwinding from a static package, where the yarn is being withdrawn with a high velocity in the direction of the package axis.

The optimal form of the package allows an optimal shape of the yarn balloon and low and steady tension even at very high unwinding velocities. Using experimental data as an input, we will calculate oscillations of yarn tension for different package geometries and winding angles. These results will be used to suggest a design new packages.
\end{abstract}

Keywords: yarn unwinding; balloon theory; simulations; design new packages

\section{Introduction}

Oscillations in the yarn during the yarn unwinding from stationary packages have a direct influence on the quality of the fabric. The characteristics of the unwinding process are thus important for production of high quality garments and should therefore be optimized. All authors (since 1950 [1-4] to 2001 [4-12]) who developed theory of unwinding yarn from packages, used a few assumptions, which help them to set the winding angle of the packages on value $0^{\circ}\left(\Phi=0^{\circ}\right)$. In practical way, the winding angle in winding machines has values from $12^{\circ}$ to $22^{\circ}$. For this reason, it is almost importance to determine the package geometry and the winding angle which allow to maximize the unwinding velocity given the allowed highest oscillations in the yarn.

\section{Theoretical part}

Angle $\phi$ is the winding angle of the yarn on the package. Its magnitude is the angle between the yarn at the unwinding point and the tangential direction at the package surface, while its signs determines whether the yarn is being withdrawn in the direction from the front end toward the rear end of the package $(\phi>0)$ or from the rear end toward the front end $(\phi<0)$ (Fig. 1). 


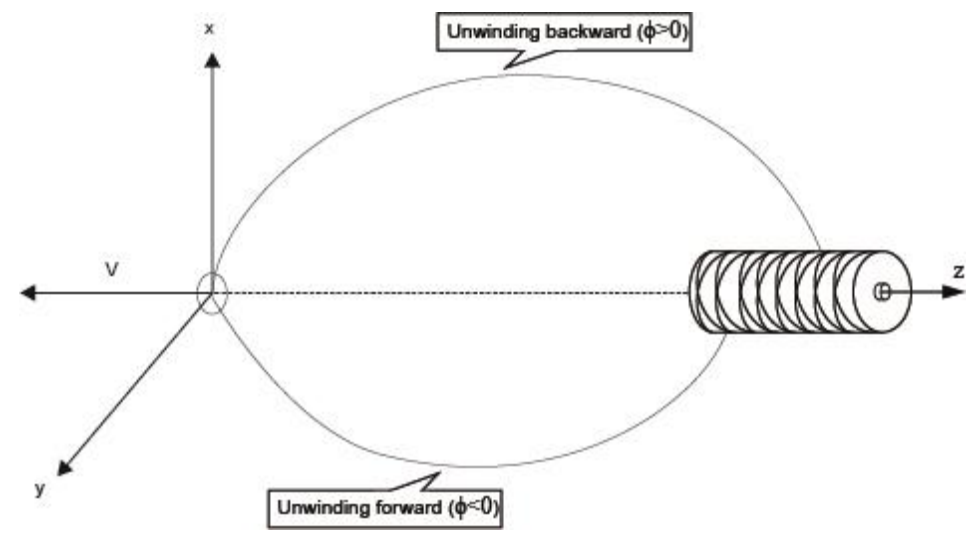

Fig. 1. Winding angle during the yarn unwinding from package

The general equation of motion which govern the motion of the yarn are known [13-40]:

$$
\rho\left(D^{2} \mathbf{r}+2 \omega \times D \mathbf{r}+\omega \times(\omega \times \mathbf{r})+\stackrel{\dot{u}}{\omega} \times \mathbf{r}\right)=\frac{\partial}{\partial s}\left(\mathrm{~T} \frac{\partial \mathbf{r}}{\partial s}\right)+\mathbf{f} .
$$

Here $\rho$ is the mass per unit length of the yarn, $\mathbf{r}$ is the radius vector to a given point on the yarn, $\mathrm{D}$ is the co-moving time derivative operator, $\mathrm{T}$ is the yarn tension and $\mathbf{f}$ is the density of external forces acting on the yarn.

Equation of motion expressed in terms of the dimensionless quantities [7].

$$
\begin{aligned}
& \overline{\mathbf{r}}=\mathbf{r}=/ c, \bar{r}=r / c, \bar{z}=z / c, \bar{s}=s / c, \\
& \bar{t}=t / \tau=\omega t, \overline{\mathbf{v}}=\mathbf{v} / V, \overline{\mathbf{v}}_{n}=\mathbf{v}_{n} / V, \\
& \overline{\mathbf{f}}=\frac{\mathbf{f} c}{\rho V^{2}}, \overline{\mathbf{n}}=\frac{\mathbf{n} c}{\rho V^{2}}, \bar{T}=\frac{T}{\rho V^{2}} .
\end{aligned}
$$

When we rewrite the equation of motion with these dimensionless quantities we obtain

$$
\bar{D}^{2} \overline{\mathbf{r}}+2 \Omega \times \bar{D} \overline{\mathbf{r}}+\Omega \times(\Omega \times \overline{\mathbf{r}})+\Omega \frac{\partial \Omega}{\partial \bar{t}} \times \overline{\mathbf{r}}=\frac{\partial}{\partial \bar{s}}\left(\bar{T} \frac{\partial \overline{\mathbf{r}}}{\partial \bar{s}}\right)+\overline{\mathbf{f}}
$$

Only one parameter remains in this equation it is the dimensionless angular velocity $\Omega$ CbV.

On cylindrical packages the angular velocity depends on the winding angle $\Phi$ according to relation $[5,6]$ :

$$
\omega=\frac{2 \pi}{t}=\frac{V \cos \Phi}{c(1-\sin \Phi)}
$$

The dimensionless angular velocity can obviously be expressed as:

$$
\Omega=\frac{\cos \Phi}{1-\sin \Phi}
$$

According to our simple model the dimensionless angular velocity thus only depends on the winding angle which will change with time because this angle is different for layers that are unwinding from front towards rear edge and those that are unwinding as the unwinding point moves from the rear towards front edge. The dependence $\Omega$ on the winding angle is shown in Fig. 2. 


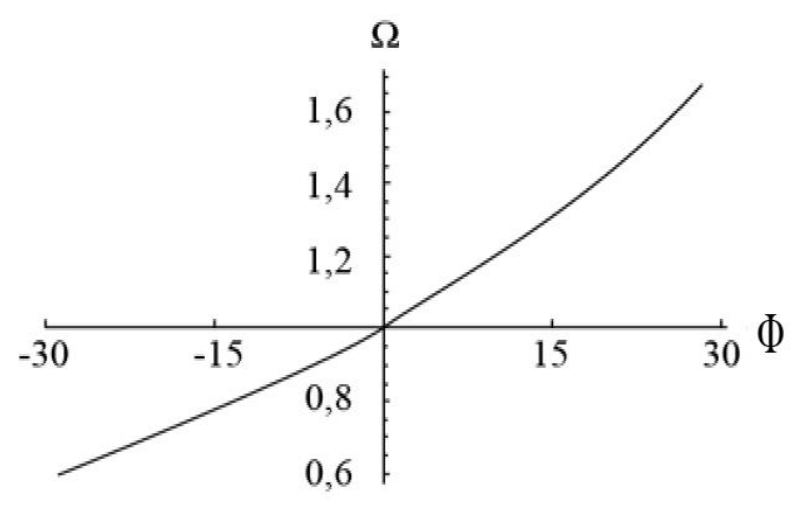

Fig. 2. Dependence of $\Omega$ on the winding angle [27-31].

During unwinding the lift-off point moves up and down the package. We can presume that the winding angle is approximately constant in the middle of the package and it changes at the edges of the package where its sign is reversed. To describe the time dependence of the winding angle we must look for a periodic function, because motion of the point is periodic to a good approximation.

The most known periodic functions are trigonometric function, such as sine function. This function should be modified so that it will change only slightly when the point moves up or down the packages. We can achieve this by raising the sine to a low fractional power, say $1 / 40$ (we have to be careful about the signs, so we take absolute value of sine function and restore the sign using the signum function [26]:

$$
f(t)=\operatorname{sign}(\sin t)|\sin t|^{\frac{1}{40}}
$$

\section{Practical part}

We measured how the tension at the eyelet depends on the angular velocity of unwinding. We measured the unwinding speed, package radius and tension of yarn as we unwound yarn from parallel cylindrical packages. We used a balloon limiter, that limits the balloon radius.

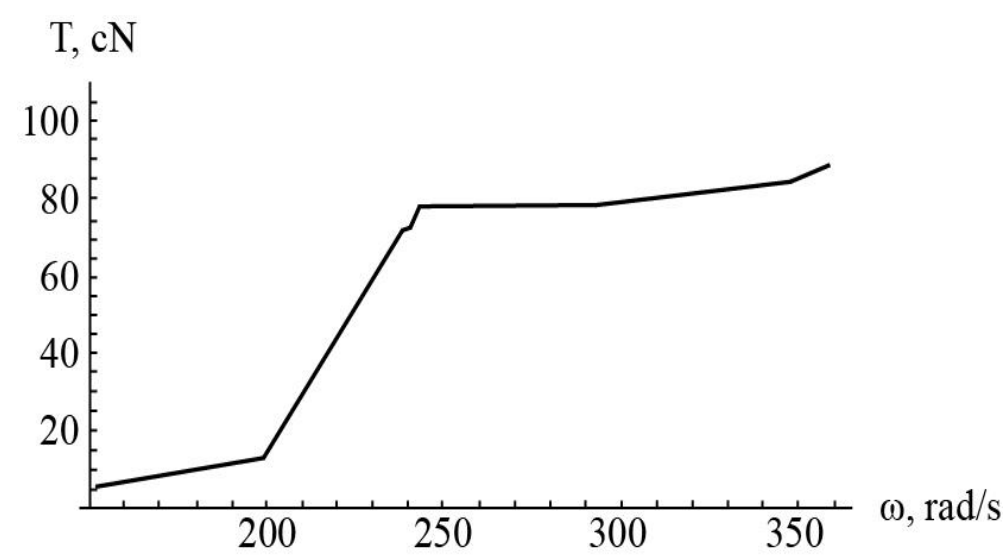

Fig. 3. Dependence of tension T on angular velocity $\omega$ of the yarn [37].

We must emphasize that this dependence was obtained by measurements on a simple, parallel wound package. In split of this we will use these date in our simulations of cross-wound packages. This approximation has little influence on the qualitative features of our results.

In our simulation, we calculate the winding angle using function (6), then we determine the corresponding angular velocity $\omega$ and finally we obtain an approximation for the tension using data from Fig. 3.

In our calculations, we considered unwinding for two consecutive layers of yarn, so that the package radius remains approximately constant during this time.

Figure 4 presents the changing tension in the yarn as we unwind yarn from a cylindrical package. The time is expressed in units of phase: $2 \pi$ corresponds to one cycle of unwinding point up and down the package. 


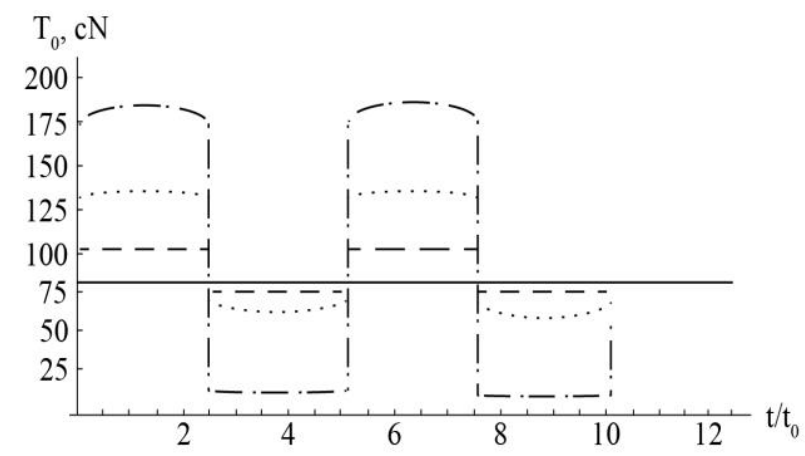

Fig. 4. Variation of the tension during unwinding, $V=1400 \mathrm{~m} / \mathrm{min}, \mathrm{c}=70 \mathrm{~mm}$. $\Phi \sim 0^{\circ}, 10^{\circ}, 20^{\circ}, 30^{\circ}$.

In a, cross-wound package with a very small $\Phi=0$ the tension is constant, since in such packages the angular velocity doesn't change with time. In packages with higher winding angle $\Phi$, the tension does change with time. This happens because the angular velocity is higher when the unwinding point moves backwards as it is when the unwinding point moves forward. The tension is a function of angular velocity, so it is oscillating. When the direction of unwinding changes near the edges of the package, the yarn tension undergoes a rapid change. Such sudden jumps lead to strong strain in the yarn, the yarn can be damaged or even broken in two parts.

Figure 5 depicts how the amplitude of oscillations depends on the package radius and winding angle:

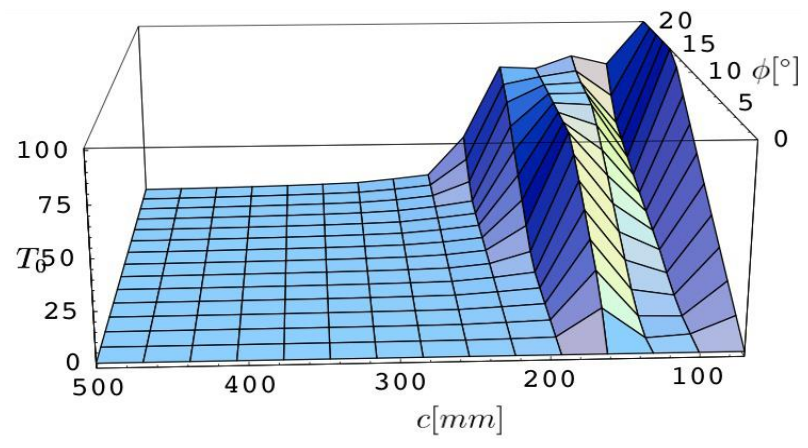

Fig. 5. Amplitude of the tension oscillation, V=2000 m/min.

\subsection{New cross-wound packages}

To reduce the tension oscillations, we devised new cross-wound packages. The package should be prepared so that the parallel wound layers are unwound when the lift-off point is moving backwards, and the interstitial cross wound layers are unwound when the lift-off point is moving forwards. This choice is motivated by the observation that cross wound packages lead to very high tensions when the yarn is unwound backwards. In addition, cross wound layers between two parallel wound layers are necessary to reduce the possibility of slips during unwinding.

In Fig. 6 we compare the amplitude of oscillations in regular and new packages. This amplitude is higher for old packages at all velocities and winding angles. The amplitude attains very high values in old packages while it is substantially lower in the new cross-wound packages.

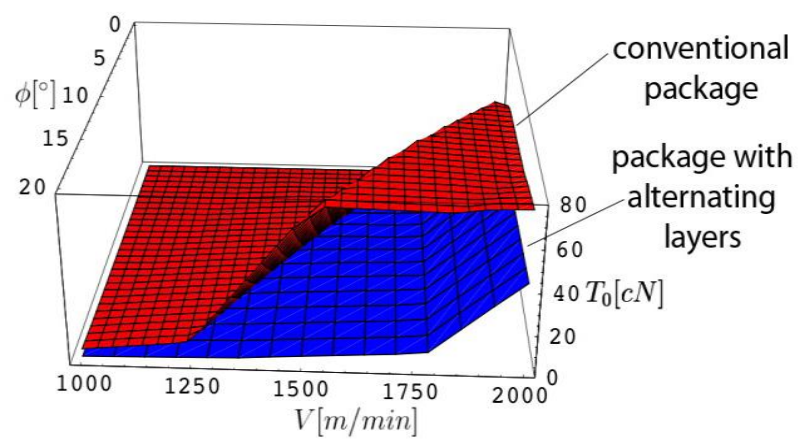

Fig. 6. Comparison of tension oscillation in regular (blue) and new packages (red), c=120 mm. 


\section{Conclusion}

We have derived the expressions for the time dependence of the angular velocity of the balloon rotation around the package axis, of the unwinding velocity and the winding angle during the yarn unwinding from cylindrical packages. The expressions allow to study the motion of the lift-off point on the package surface as we have shown. This method makes it possible to consider more general package designs where the package radius and winding angle are arbitrary functions which describe the package form and the type of winding of yarn in individual layers. This procedure allows to simulate yarn unwinding from general packages and to determine the package construction with the desired properties. We have thereby established that the parallel and the cross-wound packages differ by the absence or presence of the characteristic variations of the angular velocity and consequently the yarn tension during the unwinding. The problem of high yarn tension and its high oscillations can be avoided by constructing packages, where two types of layers are alternating, parallel layers and layer with higher winding angle. The alternating design helps to reduce sudden changes of tension, and it leads to higher stability of the unwinding process. In the near future, we would like and hopefully will implement our knowledge in the textile production and try to find out, how all research fields affect quality.

\section{References}

[1] Mack, C. (1953). Theoretical study of ring and cap spinning balloon curves. J.Text.Inst., 44, pp. 483-498, ISSN 00405000

[2] Padfielf, D.G (1956). A note on fluctuations of tension during unwinding. J.Text.Inst., 47, pp. 301-308, ISSN 00405000

[3] Padfield, D. G. (1958). The Motion and tension of an unwinding thread. Proc. R. Soc., A 245, pp. 38 2-407, ISSN 1364-5021

[4] De Barr, A. E., Catling, H. (1965). Manual of cotton spinning. Vol.5, The principles and theory of ring spinning. Textile Institut. Manchester, ISSN 00405000

[5] Kothari, V. K., Leaf, G. A. V. (1979). The unwinding of yarns from packages. Part I, The theory of yarn-unwinding. J. Text. Inst., 3, pp. 89-95, ISSN 00405000

[6] Kothari, V. K., Leaf, G. A. V. (1979). The unwinding of yarns from packages, Part II: Unwinding from cylindrical packages. J. Text. Inst., 3, pp. 96-104, ISSN 00405000

[7] Fraser, W. B., Ghosh, T. K., Batra, S. K. (1992). On unwinding yarn from cylindrical package. Proc. R. Soc., A, 436, pp. 479-498, ISSN 1364-5021

[8] Fraser, W. B. (1992). The effect of yarn elasticity on an unwinding ballon. J. Tex. Inst., 83, pp. 603-613, ISSN 00405000

[9] Fraser WB. (1993). On the theory of ring spinning. Phil. Trans. R. Soc. London, A342, pp. 439-468, ISSN 13645021

[10] Clark, J.D., Fraser, W.B., Sharma, R. Rahn, C.D. (1998). The dynamic response of a ballooning yarn: theory and experiment. Proc. R. Soc. Lond. A, 454, pp. 2767-2789, ISSN 1364-5021

[11] Fraser WB and Stump DM. (1998). Yarn twist in the ring-spinning balloon. Proc R Soc London, A454, pp. 707723, ISSN 1364-5021

[12] Clark JD, Fraser WB and Stump DM. (2001). Modelling of tension in yarn package unwinding. J Engi Mathe, 40, pp. 59-75, ISSN 0022-0833

[13] Praček, S. Jakšić, D. (2002). Theory of yarn unwinding off a package and derivation of differential equations.1, Tekstilec, 45, 5/6, pp. 119-123, ISSN 0351-3386

[14] Praček, S, Jakšić, D. (2002). Theory of yam unwinding off a package. 2, Tekstilec, 45, 7/8, pp. 175-178, ISSN 03513386

[15] Praček, S. (2004). Mathematical model for simulating yam unwinding from packages.1, Tekstilec, 47, 9/12, pp. 289291, ISSN 0351-3386

[16] Praček, S. (2004). Sliding motion of yam on the package during unwinding.1, Derivation of equations. 47, 1/2, pp. 26-28, ISSN 0351-3386

[17] Praček, S. (2004). Sliding motion of yam on the package during unwinding. 2, Tekstilec, 47, 7/8, pp. 229-231, ISSN 0351-3386

[18] Praček, S. (2005). Mathematical model for simulating yam unwinding from packages. 2, Tekstilec, 48, 7/9, pp. 173176, ISSN 0351-3386

[19] Praček, S. (2005). Virtual forces in the mathematical model of yam unwinding. 1, Tekstilec, 48, 10/11, pp. 252254, ISSN 0351-3386

[20] Praček S, Jakšić D. (2005). Yarn unwinding from package s - discussion of kinematic and dynamic properties of yarn. Strojniški Vestnik, 51, 2, pp. 74-89, ISSN 0039-2480

[21] Praček, S. (2006). Virtual forces in the mathematical model of yam unwinding. 2, Tekstilec, 49, 1/3, pp. 5-7, ISSN 0351-3386

[22] Praček S. (2007). Theory of string motion in the textile process of yarn unwinding. International journal of nonlinear sciences and numerical simulation, 8. 3, pp. 451-460, ISSN 1565-1339 
[23] He, Ji-Huan; Zhang, Li-Na (2008). On Convergence Point of the Two-strand Yarn Spinning Textile Research Journal. vol. 78,11, pp.1022-1024, ISSN 0040-517

[24] Yang, Rui-Huan; Wang, Shan-Yuan. (2009). Determination of the Convergent Point in the Rotor-spun Composite Yarn Spinning Process Textile Research Journal. vol. 79, 6, pp.555-557, ISSN 0040-517

[25] Praček, S. and Sluga, F. (2010). Numerical simulations of yarn unwinding from packages. Mathematical and computational applications in science and engineering, vol. 15, no. 5, pp.846-852, ISSSN 1300-686X

[26] Praček, S. Sluga, F. (2010). Matematical model for yarn unwinding from packages. Mathematical and computational applications in science and engineering, vol. 15, no. 5, pp.853-858, ISSN 1300-686X

[27] Praček, S. (2010). Theoretical model of unwinding process from packages, Annals of DAAAM for 2010 \& Proceedings of the 21 st International DAAAM Symposium, 20-23rd October 2010, Zadar, Croatia, ISSN 17269679, ISBN 978-3-901509-73-5, Katalinic, B. (Ed), pp. 1469-1470, Published by DAAAM International Vienna, Vienna

[28] Praček, S. (2010). High-speed yarn transport systems simulation, Annals of DAAAM for 2010 \& Proceedings of the 21 st International DAAAM Symposium, 20-23rd October 2010, Zadar, Croatia, ISSN 1726-9679, ISBN 9783-901509-73-5, Katalinic, B. (Ed), pp. 1471-1472, Published by DAAAM International Vienna, Vienna

[29] Praček, S. Sluga, F. Možina, K. Franken, G. (2011). Unwinding from cylindrical packages, Annals of DAAAM for 2011 \& Proceedings of the 22 st International DAAAM Symposium, 23-26th November 2011, Vienna, Austria, ISSN 1726-9679, ISBN 978-3-901509-83-4, Katalinic, B. (Ed), pp. 0917-0918, Published by DAAAM International Vienna, Vienna

[30] Praček, S. Sluga, F. Možina, K. Franken, G. (2011). Cylindrical packages simulations, Annals of DAAAM for 2011 \& Proceedings of the 22 st International DAAAM Symposium, 23-26th November 2011, Vienna, Austria, ISSN 1726-9679, ISBN 978-3-901509-83-4, Katalinic, B. (Ed), pp. 0919-0920, Published by DAAAM International Vienna, Vienna

[31] Praček, S. Sluga, F. Možina, K. Franken, G. (2011). Conic packages oscillations, Annals of DAAAM for 2011 \& Proceedings of the 22 st International DAAAM Symposium, 23-26th November 2011, Vienna, Austria, ISSN 17269679, ISBN 978-3-901509-83-4, Katalinic, B. (Ed), pp. 0921-0922, Published by DAAAM International Vienna, Vienna

[32] Praček, S. Možina, K. Sluga, F. (2012). Yarn motion during unwinding from packages. Math. comput. model. dyn. syst., vol. 18, 6, pp. 553-569, ISSN 1387-3954

[33] Praček, S. (2013). Theory of yarn dybamics during unwinding from packages. Adv. mat. res. vol. 601, pp. 275-279, ISSN 1662-8985

[34] Praček, S, Sluga, F. Možina, K. (2012). Mathematical model for yarn unwinding.1, Adv. mat. Res., vol. 403-408, pp. 5131-5135, ISSN 1662-8985

[35] Praček, S. Sluga, F. Možina, K. (2012). Mathematical model for yarn unwinding. 2, Adv. mat. res., vol. 403-408, pp. 5136-5141, ISSN 1662-8985

[36] Praček, S. (2013). Model for yarn transport systems. Adv. mat. res., vol. 601, pp. 237-241, ISSN 1662-8985

[37] Praček, S. Nace, P. Simončič, B. Petra, Eva, F.T. (2015). Model for simulating yarn unwinding from packages. Fibres \&Textiles in Eastern Europe.,23.2(110), pp.25-32, ISSN 1230-3666

[38] Praček S, Pušnik N, Franken G, and Simončič B. (2016). Balloon theory of yarn during unwinding from packages. Text. Res. J., 86, 14, pp. 1522-1532, ISSN 0040-5175

[39] Praček, S. Pušnik, N. (2016). Fictitious forces in yarn during unwinding from packages. Textile research journal, ISSN 0040-5175

[40] Pušnik, N. Praček, S. (2016). The effect of winding angle on unwinding yarn. Transactions of famena, vol. 40, iss. 3, pp. 29-42, ISSN 1333-1124 